\title{
HET FORT TE KARTASOERA IN 1741.
}

Bijna even lang als Nederland een afzonderlijke staat vormt in Europa, is ook reeds zijn invloed in de Indische Archipel en bepaaldelijk op Java gevestigd geweest. Slechts enkele malen is onze onafhankelijkheid bedreigd, maar ons gezag op Java heeft meermalen in een gevaarlijken toestand verkeerd, door opstand van de inlandsche en soms van de Chineesche bewoners van dat eiland. Nimmer was dit meer het geval dan, na het voorgevallene in October van het jaar 1740, dat bekend is onder de naam van de moord der Chinezen te Batavia door Valckenier. De berigten hiervan kwamen ter ooren van hun landgenooten, die in de zoogenaamde Stranddistricten van het rijk van Mataram, de tegenwoordige residenties Tagal, Pekalongan, Samarang, Japara en Rěmbang, gevestigd waren, en die dien ten gevolge begonnen zamen te scholen en een verdachte houding aan te nemen. Dit was zeer naar de zin van den Soesoehoenan Pakoe Boewånå II, (1), die, opgestookt door zijn Rijksbestierder Nåtå Koesoemå (2), hierin een schoone gelegenheid meende te zien om zich van de Compagnie en haar invloed in zijn rijk te ontslaan. Hij zond daarom een van zijn Regenten naar de Chinezen om hen aan te moedigen, en, onder de schijn van de Hollanders te waarschuwen en te helpen, deze in de strik te lokken. Zoo begon dan nu weder die Javaansche taktiek, reeds vroeger tegen de Hollanders gebezigd, waarvan voor 60 jaren Kapitein Tak in de opstand van Soeråpati het slagtoffer was geworden. Omdat hierin de Chinezen de hoofdrol spelen, is deze oorlog bekend onder de naam van de Chinesche oorlog. Een belang- 
rijke episode daarvan is de verovering van het fort te Karıasoerå in 1741 door de Javanen. Vrij uitvoerig is dit reeds medegedeeld door VAN KAMPEN, in zijn Geschiedenis der $N e$ derlanders buiten Europa, deel III, stuk 1, p. 37-39; als bronnen voor zijn verhaal noemt hij DUBoIs, Vies des Gouverneurs-Généraux en CRAWFURD, History of the Indian Archipelago, deel II, p. $363 \mathrm{enz}$. Deze laatste zegt uit inlandsche bronnen geput te hebben, waarmêe hij zeker de Javaansehe Babads of geschiedenissen bedoelt Daar ook rafFles, History of Java, deel II, p. 218, slechts in 't voorbijgaan hiervan spreekt, ofschoon hij anders het in dezen tijd gebeurde uitvoerig verhaalt, scheen het niet onbelangrijk eens mede te deelen, hoe zulk een Babad dit voorval vertelt, en daarmeê een proefje te geven van de wijze, waarop de Javanen hun geschiedenis schrijven.

De kommandant van het fort wordt bij VAN KAMPEN niet genoemd, maar hageman, Handleiding tot de kennis der Geschiedenis van Java, deel I, p. 192, noemt hem vaN velzen, en zegt dat hij van een Javaansche vrouw te Japara geboren, en een woestaard in zijn handelingen tegen de Inlandsche Vorsten was. Dit komt overeen met hetgeen de Babad ons vertelt: daarin toch wordt hij op een paar plaatsen Lapèl en later Pan Pèlser geheeten en ook als overmoedig en trotsch voorgesteld. Terwijl de Chinezen an het Noorderstrand, zoo niet van de openlijke, dan toch van de geheime hulp van de Javanen verzekerd, meer en meer de Hollanders in het naauw brachten, zoodat deze de hulp van de Javanen inriepen, speelden de Soesoehoenan en zijn Visier Nåtå Koesoemå hun valsche rol voort. Immers zij gaven gehoor aan het verzoek van den kommandeur van Samarang en zonden hulptroepen - evenwel met last om niets uit te voeren, - maar zetten tevens de Chinezen te Kartåsoerå aan, om zich van daar te verwijderen. Daarop lieten zij hen wederom door Javaansche troepen vervolgen, die na eenige schoten met los kruid met hen gewisseld te hebben, terug trokken. De Chinezen vereenigden zich met hun verspreide landgenooten en legerden zich te Sarådjå. Van de andere kant trokken ook die van Tagal en Pekalongan bijeen en bezetten, onder aanvoering van Moeda Tjoepjan, de plaatsen Lemahbang en Barĕgas, waar door de gemeenschap tusschen Samarang en Kartåsoerå werd afgebroken, en de bezetting van het fort in deze laatste hoofdplaats in een onaangename positie geraakte; die niet beter werd, toen de kom- 
mandant in een hofintrigue gewikkeld werd, die door de Babad op de volgende wijze verhaald wordt.

Er waren twee Pangérans, genaamd Wirå Menggålå en Tepå Sånå, neven van den Soesoehoenan (3); de eerste ontzag zich niet met zijn volgelingen te spreken over een aanstaande verandering in de regering, daarbij zelfs zijdelings op zijn broeder Tepå Sånå als de vermoedelijke vorst doelende. Dit bleef natuurlijk niet onopgemerkt, vooral bij den Rijksbestierder Nåtå Koesoemå. Hierbij kwam nog, dat Pangeran Tepå Sånå tot schoonzoon had angenomen een zekeren Poespå Dirdjå, zoon van een gewezen Regent van Batang. Ook vertelde men, dat deze Poespå Dirdjå voor Tepå Sånå in bewaring had 4 kisten met geld, doch ze nu onlangs naar het fort had overgebracht. Dit alles werd door een zekere Loerah Djajantåka aan den Rijksbestierder medegedeeld, die nu voor zamenspanning van de Javaansche Prinsen met de Hollanders begon te vreezen, en in elk geval voor ontdekking van de Javaansche politiek in de Chinesche oorlog. Hij gaf er dus den Soesoehoenan kennis van. Deze antwoordde hem, reeds vroeger iets vernomen te hebben van de slechte gezindheid van den afgezetten Regent van Batang, Poespå-Tenåjå, en van zijn zoon, en dus $\mathrm{nu}$ best oordeelde hen te vatten en te dooden. Nadat zij gegrepen waren, werd hiervan aan den Kommandant van Velzen mededeeling gedaan, die vooral met Poespa-Dirdjå in betrekking had gestaan. Hij zag in, dat de zaak niet regt in orde was, en bekende nu, dat Poespå Dirdjå bij hem was gekomen met een verzoek van Pangéran Wirå Měnggålå, om 4 kisten zoolang in zijn hoede te nemen, die deze in zijn huis niet te best vertrouwde; hij had er toen geen kwaad in gezien en ze aangenomen, maar nu was hij allezins bereid ze tot onderzoek over te leveren. Toen de kisten opengebroken waren, werden er gebakken steenen in gevonden. Dit makte den Kommandant woedend, toen hij zag de dupe van de Javanen geweest te zijn, zoodat hij nu ook 7 brieven van TepåSånå overgaf, die er allen op waren ingerigt om hem op te stoken en den Vorst in een slecht daglicht te stellen. Van alles werd aan den Soesoehoenan rapport gedaan, en de beide gevangenen op zijn bevel gedood. Hiermede was evenwel de Rijksbestierder niet te vreden; hij achtte de beide Pangérans nog gevaarlijk, vooral Tepå Sånå. Openlijk durfde hij ze evenwel niet aan, en om 's Vorsten toestemming te vragen vreesde 
hij ook; daarom wist hij door tusschenkomst van Raden Arjå Malajå-Koesoemå, een bloedverwant van Tepå Sånå, dezen zijn achterdocht te ontnemen, en hem met zijn zoon Djåjå Koesoemå bij zich aan huis te lokken, waar hij ze gevangen zette en 'savonds liet worgen. Dit was een wederregtelijke handelwijze, een onwettige strafoefening, volgens het oordeel van den geschiedschrijver. Men had Tepå Sånå alleen een eed van getrouwheid moeten afnemen. Het laat zieh denken, dat Pangéran Wirå Menggålå hierin een wel gegronde voorspelling zag van het lot, dat hem wachtte; hij ging daarom met zijn familie en die van zijn broeder en neef heimelijk weg. De hoofden, met zijn vervolging belast, slaagden er niet in hem te vatten, en hij bereikte ongedeerd de grenzen van Samarang, doch stelde zich, tot zijn ongeluk, in handen van den Chinees Singsèh, die met zijn natie en vereenigd met den Javaanschen Regent van Grobogan, Martå Poerå, welke op 's Vorsten bevel opstandeling was geworden, thans voor het fort van Samarang was gelegerd. Singsèh, die verpligting had aan den Soesoehoenan en op nog meer bijstand hoopte, was verlegen met de zaak, waarop Martå Poerå hem ried er te Kartåsoerå kennis van te geven, en te vragen wat de Vorst verlangde, dat met de weggeloopen Prinsen zou gedaan worden. Hier scheen men de eene dienst de andere waard te beschouwen, en daarom zich verpligt te rekenen het masker af te werpen, en openlijk de Hollanders aan te vallen. Dien ten gevolge werd de Rijksbestierder gelast het fort aan de Noordkant te omsingelen; de Binnenwedånås (4) kregen bevel de Zuidkant aan te vallen, en het werk aldus onder hen verdeeld: Toeměnggoeng Rådjå Niti moest een opening in de muur aan de Zuidkant maken; Toemenggoeng Nåta Joedå en Wirå Djåjå moesten zich posteren op de Sitînggil (5) en de palisadering aan de Westerkant omverhalen, terwijl de beide Toemĕnggoengs Wirå Rědjå en Tirtå Wigoenå met de wacht aan de poorten Kamandoengan en Gapit (6) werden belast. Voorts ontbood de Radèn-Adipati (Rijksbestierder) de Toemenggoengs van Noembaq en Anjar Sèwoe, benevens den Regent van Banjoemas, om hen in het fort te zenden, onder het voorwendsel, dat ze hun opwachting kwamen maken bij den Kommandant, dewijl ze met hun volk naar Bahrawa gingen om Ariå Pringgålajå tegen de Chinezen te helpen. De troepen waren reeds op de Palataran (het voorplein) van den Rijksbestierder geschaard ten getaie van 700 man, doch op aan- 
raden van Radjå Niti werd de zaak tot de volgende Donderdag uitgesteld; bovendien werd nog afgesproken, dat het teeken voor den aanval zou zijn, dat de Kalangs (7) bij het fort aankwamen.

Toen nu die Donderdag daar was, gingen de Toemĕnggoengs Djåjå Soedirgå, Mangoen Negårå en Joedå Negårå, met den Kliwon Ngabèi Mangoen Joeda, het fort binnen en werden aan den Kommandant voorgesteld als aanvoerders van hulptroepen naar Sålåtigå tegen de Chinezen, en werd hem tevens medegedeeld, dat men nog maar op de komst van de Kalangs wachtte. De Kommandant antwoordde, dat hij ze zou ontvangen, daar hij het aantal van de troepen wenschte te weten. Intusschen hadden de overige aanvoerders hun taak begonnen, zonder door de Hollanders bemerkt te worden. De lijfwacht (kaparak) stond op de Sitînggil onder Nåtå Joedå en Wirå Djåjå; de Abdi Gědong (8) hadden de wacht bij de Sri Menganti (9), terwijl Rådjå Niti des nachts reeds was begonnen te breken aan de muur, om door een opening daarin van ter zijde aan te vallen. In het fort werd nog steeds gewacht op de Kalangs; eindelijk ging de Mantri Soetå Joedå naar buiten om eens naar hen uit te zien, terwijl Mangoen Negårå aan den Kommandant vroeg; wat hij verlangde dat geschieden zou, als zij kwamen. Hij antwoordde, dat hij ze zou begroeten en een glas arak geven. In de verschijning van Soeta Joedå meenden de buiten het fort staande Javaansche hoofden het afgesproken teeken te zien, en lieten op de Hollanders die op de Aloenaloen bij de Warîngin Binatoer (16) waren, schieten, zonder hen evenwel te raken; de Hollanders vlugtten daarop naar het fort. Van Velzen vroeg natuurlijk, wat dit beteekende, waarop Soetä Joedå en Goenå Wongså hun krissen trokken en naar hem staken. Hij sprong achteruit, weerde met een stoel de steken af en liet de poort sluiten, terwijl hij naar boven op zolder (?) klom, en met 20 van zijn slaven tegen de Javanen begon te vechten. Dezen waren verbijsterd, duwden en drongen elkander; en velen van hen sneuvelden door het schieten van van Velzen en zijn volk. De andere Hollanders bleven op de muur en losten de kanonnen op de Javanen, die voor de poort stonden, zoo dat zij die niet konden naderen, en dus hun landgenooten, die er binnen waren, niet verlossen; van deze werden Mangoen Negårå en Djåjå Soedirgå met kolfslagen afgemaakt, terwijl Joedå Negårå dit lot gelukkig ontkwam. Toen Nåtå VI. $(X)$ 
Joedå en Wirå Djåjå het schieten hoorden, gaven zij last de omheining van het fort omver te halen, doch dit mislukte insgelijks door het schieten der Hollanders; terwijl ook Rådjå Niti, die in het eerst met zijn volk over de muur kwam, met zulk een hevig vuur werd ontvangen, waardoor onder anderen Demang Kondoer sneuvelde, dat hij terug moest trekken en door de Hollanders tot op de Sitînggil vervolgd werd. Daar bleef Nåta Joedå onbeweeglijk in het midden van de kogelregen staan, daar hij in de heilige krijg wilde sterven. Ook Ngabèi Djåjå Sontå sneuvelde, door een kogel aan het hoofd getroffen, benevens Asmarandånå, en Djåjå Sontâ's zoon, Djåjå Dirå, die zijn vaders lichaam wilde mêevoeren. Zoo bleven de Hollanders aan alle kanten overwinnaars. De Rijksbestierder, het schieten hoorende, deed zijn wapenen om en ging naar de BuitenPaséban, waar de troepen geschaard stonden; gelastte daarop aan Soerå Djajå hem met al het volk naar het strijdperk te vergezellen. Onderweg evenwel, kwam een van de vlugtelingen hem tegen, die voor hem boog en uitriep: "Helaas, Heer! uw knechten hebben tegenspoed, want zij zijn niet allen binnen het fort kunnen komen; alles is ontdekt. Zij, die er binnen waren, zullen, denk ik, verloren zijn. Toemĕnggoeng Mangoen-Negårå is met zijn onderhoorigen waarschijnlijk reeds dood, daarom is het verkieslijk voor u om terug te trekken en eerst met de Boepatis te beraadslagen. Ga niet te spoedig naar het fort, het zou evenzoo zijn als een vlieg, die in het vuur vliegt.” Nåtå Koesoemå volgde deze raad op, en keerde terug. Hij gaf bevel het fort te omsingelen, en ging zelf naar de Kraton. De Soesoehoenan zeide: tot hem: "Wel, Patih, wat denk je wel, nu je onderneming zoo ongelukkig is afgeloopen?" De Rijksbestierder antwoordde: "Heer! Die rampspoed is ontstaan, doordien een gek heeft laten schieten op de Hollanders vóór de bepaalde tijd; ik stel mijn leven in uw handen." De Vorst antwoordde: "Nu genoeg, Patih; wat zal men er van zeggen; het is gedaan; maar stuur nu iemand naar Martå Poerå, om, gezamentlijk met een Martå-Loeloet (11), Wirå Měnggålå, onzen broeder, van den Chinees Singsèh op te eischen, omdat ge nu de krijg met de Hollanders begonnen bent." De RadènAdipati stelde nu nog voor om Pringgålåjå, die tegenover de Chinezen te Sålåtigå stond, en Malåjå Koesoemå, die de Pangerans vervolgd had, terug te roepen, wat door den Vorst werd goedgekeurd, en waarna hij zich verwifflerde. Arjå Dikårå 
werd door hem met den Martå Loeloet naar Samarang gezonden, om 's Vorsten bevel aangaande Wirå Menggålå te volbrengen. Singsèh was dan ook zeer verheugd over het berigt van het gebeurde te Kartåsoerå, en leverde den ongelukkigen Prins en Raden Wirat Medjå, een neef, met hun families over; beide werden door Arjå Dikårå geworgd, en te Goenoeng Pragotå begraven (12).

Het fort te Kratåsoerå was door de Javanen geheel ingesloten; doch men vroeg nog hulp aan den Chinees Singsèh, die daarop 500 man zond, onder bevel van Pingboeloeng, Héjang, Hetik en Po. Deze, te Kartåsoerå gearriveerd zijnde, vertelden, dat Singsèh alleen op een bevel van den Soesoehoenan wachtte om het fort van Samarang aan te vallen, en dat zij bereid waren dat te Kartåsoerå te verdelgen. Zij stelden nu voor om het fort eerst met de groote kanonnen te beschieten, en daarna te amokken. Dit keurde de Rijksbestierder goed, en gaf de kanonnen met toestemming van den Soesoehoenan aan hen over. Dit waren nu de stukken: Ki Koembåråwå, Koembarawi, Koembå Aswani Koembå, Soebrartå, Segårå Wånå, Pamětjoek, en Ki Goentoer Gĕni (13); het laatste kanon werd doorgaans slechts met 40 katjes kruid geladen; de Chinezen deden er 80 in met kogels naar evenredigheid, zoodat de loop bijna geheel vol was. De Sarå Gerni (14) waarschuwden, dat dit de maat niet was, en het misschien ongelukken zou veroorzaken. De Chinezen verzochten hen maar te zwijgen: want, zeiden zij, de Javanen vechten niet zoo als wij, en zijn met het behandelen van kanonnen niet bekend. Het stuk werd afgeschoten; de kogels vielen op het fort, dat de Hollanders verbaasde, (zouden de Javanen er vroeger over heen geschoten hebben?) die evenwel dadelijk antwoordden. De Chinezen schoten onophoudelijk door, totdat eindelijk door het vele schieten de stukken sprongen en vele manschappen gedood werden. De belegering werd evenwel krachtig doorgezet, zoodat de bewoners van Kartåsoerå ongerust werden door de vele kogels, die op de huizen en de kraton vielen.

Middelerwijl kwam er nog een Chinees, Sa Pandjang geheeten, met 1000 man uit Batavia te Kartåsoerå aan. Door den Rijksbestierder naar de staat van zaken te Batavia ondervraagd, antwoordde hij, dat daar de kans nog gelijk stond, doch dat hij gekomen was om de agreatie van den Soesoehoenan en den 
Rijksbestierder te vragen. . Deze zeide hem, dat hij eerst de vuiligheid op de hoofdplaats moest schoonmaken, omdat de Vorst daar nog veel onreins had. Sa Pandjang beloofde daartoe zijn hulp, daar de Chinezen liever op de Aloenaloen wilden sneuvelen, dan een ellendige dood te Batavia sterven. Hij kreeg zijn kwartieren ten oosten van de Kadipaten (15), en zijn troepen zwierven in den omtrek rond. De Soesoehoenan ontving ıu den Chinees bij de Régol (Buitenpoort) en beschonk hem met kleederen en geld. De volgende dag kwam hij bij den Rijksbestierder met het voorstel een soort van schutdak (16) van. groote balken met ijzer beslagen en op rollen te maken, daaronder zouden de Chinezen het fort naderen, om het aan te vallen en amok te maken. Maar, aangezien men zeide, dat vóór de muren allerlei messen, bij wijze van borangs (randjoes) in de grond zaten, verzoekt hij, dat eenige parden en buffels vóór de slagorde uitgejaagd zouden worden, om die te vertrappen! De Radèn Adipati keurde deze voorslagen goed, en Sa Pandjang ging zijn volk gelasten zulk een toren te maken. De Hollanders binnen in het fort kregen langzamerhand gebrek aan rijst. Daarom hield de Kommandant raad met den Luitenant en Secretaris, tot hen zeggende: "Als die belegering zoo voortduurt zullen wij stellig van honger sterven; ook is het geen gelijk gevecht, 't is zoo goed alsof wij door bergen overstelpt worden." De Luitenant Kélas (?) antwoordde, dat hij geen andere raad wist te geven, dan tusschen twee dingen te kiezen, namelijk leven of dood; koos men de dood, dan moest men zich blijven verdedigen, en het ergste verwachten; koos men het leven, dan moest men zich onderwerpen. De Kapitein stelde nu voor een brief aan den Vorst te schrijven, dat aangenomen werd. De brief geschreven zijnde, werd door een paar koelis naar de verschansing van de Javanen gebracht; zij waren evenwel bevreesd en handelden als dieven door de brief ter sluiks voor de verschansing te werpen, waar hij 's morgens door den wacht werd gevonden, die, ziende, dat hij aan den Soesoehoenan was geaddresseerd, hem aan den Rijksbestierder zonden. De Vorst ontving door hem de brief, waarvan de inhoud was, dat de Kapitein vergiffenis vroeg, en verzocht dat de Vorst aan zijn Boepati's zoè gelasten met schieten op te houden. Tevens makte hij bekend, dat de Hollanders gebrek aan levensmiddelen hadden, waarom hij verzocht, dat men hun rijst zou zenden. Aan 
Tirtå Wigoenå werd gelast een antwoord op te stellen, dat door de wacht voor het fort werd neêrgeworpen; daar werd het opgenomen en aan deh Kommandant gebracht, die het door den translateur liet voorlezen: de inhoud was een weigering van het verzoek. De Hollanders waren verslagen. Luitenant Kélas zeide, dat er niet meer over viel te praten, men moest kiezen tusschen dood en onderwerping. De Kapitein zond nu een trompetter om de witte vlag bij de poort uit te steken. Op dit gezigt begonnen de Javanen te juichen, het. welk de Hollanders deed denken, dat hun onderwerping niet werd aangenomen, zoodat zij hun kanonnen weêr laadden; doch toen zij bemerkten, dat er verder geen gevolg van kwam, werd de trompetter buiten gezonden naar de verschansing van de Javanen. Daar gekomen zijnde, verzocht hij bij den Rijksbestierder gebracht te worden. Men maakte evenwel zwarigheid hem zoo ongeboeid toe te laten; hij moest er in toestemmen zich de handen van voren bijeen te laten binden, en zoo tusschen twee rijen gewapenden voor Nåtå Koesoemå geleid te worden. Aan deze verklaarde hij door den Kapitein gezonden te zijn om hun onderwerping aan te bieden, met verzoek dit aan den Soesoehoenan mede te deelen. Dadelijk werd nu een bode naar de Sri Mĕnganti gezonden; Toemĕnggoeng Tirtå Wigoenå nam het berigt aan en deelde het den Vorst mede, die liet zeggen, dat hij het aan den Radèn-Adipati overliet, maar dat hij voorzigtig moest zijn, en de stukken laden. Deze zeide toen tot den trompetter, dat, als de Kapitein zijn overgave ernstig meende, hij de volgende morgen om 7 uur met zijn volk buiten het fort moest komen, met de wapens in bundels zamengebonden. Toen dit antwoord overgebracht was, werd er weêr raad gehouden, waarin de Luitenant zeide: "geen lang beraad, laten wij maar slaven worden." Zoo geschiedde het dan ook. De wapens werden bij elkander gebonden en zelfs de buitgemaakte krissen en pieken in kisten gepakt. Van zijn kant gaf de Rijksbestierder bevel aan Raden Arjå Pringgålåjå de Hollanders bij hun uittogt te gemoet te gaan.

Op de volgende morgen geschiedde alles volgens de gemaakte afspraak. Het garnizoen van het fort, 450 man in getal (17), trok de poort uit, en werd door Pringgålåjå ontvangen. De drie officieren begroetten hem en smeekten om medelijden. Hij vroeg nadere bevelen aan den Rijksbestierder, die hem gelastte den Kapitein zelf bij zich te houden; de Luitenant werd aan 
Toemenggoeng Tirtå Wigoena, de Secretaris aan Toeměnggoeng Rådjå Niti toegewezen; de troepen moesten evenzoo onder de andere Javaansche hoofden verdeeld worden. Deze bevelen werden aan den Kapitein medegedeeld, die alleen ten antwoord gaf, dat hij er in berustte, want hun leven was in handen van den Vorst. De Secretaris vroeg nu nog, hoe men met de buitgemaakte Javaansche wapenen wilde handelen; ook hierin werden bevelen van den Soesoehoenan gevraagd, die nu Arjå Mandoerå zond om ze in ontvangst te nemen en te ge. lijk het fort te inspecteren, of er soms ook nog hinderlagen gelegd waren. Dit geschiedde, doch er werd niets gevonden: de wapenen werden den Vorst aangeboden. Na verloop van drie dagen verlangde hij de sterkte eens te bekijken; bij deze gelegenheid vroeg hij naar velerlei dingen en was verbaasd over de inrigting en uitrusting. Hij gelastte toen de grachten aan te vullen, en de woonhuizen af te breken. Alle dingen van waarde, goud, zilver, muntstukken en andere voorwerpen, werden naar de Kraton overgevoerd; het verhaal zegt, dat dit drie dagen duurde. Er werden nog 117 geweren gevonden. Alles wat er gevonden was, werd onder 's Vorsten dienaren verdeeld: de Rijkssbestierder alleen begeerde er niet van. De gevangen soldaten werden besneden en onderwezen in de Javaansche godsdienst, zooals de Babad zegt.

Dewijl nu deze aanslag tamelijk gelukt was, en de Hollanders er reeds tijding van gekregen hadden, zoodat het noodzakelijk was met kracht het fort te Samarang aan te tasten, werden daarheen de Chinezen, die nog op de hoofdplaats waren, en versche Javaansche hulpbenden gezonden. Maar tevens stelde nu de Rijksbestierder aan den Vorst voor de drie Hollandsche opperhoofden te dooden, daar zij anders misschien aanslagen mogten beramen. Dit keurde de Vorst goed. De Regenten, die met hunne bewaking belast waren, kregen nu bevelen hiertoe. De Kapitein werd daarop door Pringgålåjå in de rivier Pépé gedood; en ook de Secretaris, maar de Luitenant ontging dit lot. Tot zoo ver de Babad hierover. Hoe en waardoor het kwam, dat de Luitenant aan de dood ontsnapte, blijkt niet. De wijze, waarop deze moord volbracht werd, wordt evenmin verhaald. De meeste Europesche schrijvers zeggen, dat zij dood geknuppeld werden, hierin CRAWFURD volgende, die dit, naar zijn zeggen, op gezag van inlandsche bronnen opneemt. RAFFLES ook in het bjjzonder van dit feit 
geen melding maakt. De Javaansche overleveringen zelf schijnen dus ook hierin niet geheel eenstemmig te zijn. Behalve dit worden in het verhaal van DUBOIs nog andere afwijkingen gevonden, die evenwel op minder goede gronden schijnen te berusten.

Uit het bovenstaande kan wederom blijken, dat de vergelijking van Inlandsche berigten voor onze geschiedenis van de Indische Archipel in de beide laatste eeuwen ook nu nog niet geheel van belang ontbloot is; vooral wanneer het feiten geldt, waaromtrent de Europeërs, zooals hier, niet dan gebrekkige en verkeerde mededeelingen bij het eerste onderzoek konden verkrijgen. 


\section{AANTEEKENINGEN.}

(1) Soesoehoenan Pakoe Boewånå II was in 1727 als tienjarige knaap zijn vader Praboe Mangkoerat opgevolgd. Hij was een kleinzoon van Soenan Poeger die in 1705 zijn neef Mangkoerat Mas met de hulp van de Hollanders van de troon verjoeg. Hij regeerde tot 1749 , en was zeer ongelukkig in zijn bestuur, daar hij zich zelf in ongelegenheid bracht door zijn dubbelzinnige houding tegen de Hollanders en Chinezen beide, en ook dewijl onder hem de oorlog is begonnen, die met de verdeeling van het rijk is geëindigd.

(2) De Rijksbestierder Nåtå Koesoemå had groote invloed op den Soesoehoenan, en was een vijand van de Hollanders; hij was dan ook de grootste en voornaamste bewerker van al hetgeen er in deze tijd voorviel.

(3) Tepå Sånå en Wirå Menggålå waren zonen van den in 1708 naar Ceylon verbannen Soesoehoenan Mangkoerat Mas (Vgl. boven aant. 1), en hadden dus ook wel eenig regt op den troon, van daar dat de verhouding tusschen hen en de regerende Vorst natuurlijk zeer gespannen was.

(4) De Binnen-Wedånås zijn 4 ambtenaren van de hoogste rang binnen de kraton. Twee zijn bevelhebbers van de lijfwacht (Wedånå kaparaq), en twee zijn belast met het opzigt over de uitgaven en de vooraad van den Vorst (Wedånå Gĕdong).

(5) Sitînggil beteekent hooge grond, het is de plaats, waar de Vorst zich bevindt, als hij zich in het openbaar vertoont.

(6) Dit zijn twee poorten, in de kraton staande tusschen de Sitînggil en de eigentlijke woning van den Vorst.

(7) Kalangs worden genoemd een soort van menschen, in de nabijheid van Soeråkartå wonende, die, volgens de Javaansche overlevering, uit de coïtus van een hond met een vrouw zijn ontstaan; er is een Wedånå over hen aangesteld. Zij schijnen ook als troepen gebruikt te worden.

(8) Met Abdi Gĕdong wordt bedoelt het volk, dat onder de beide Wedånås Gëdong (zie boven aant. 4) staat. 
(9) Sri Mĕnganti is de naam van een poort in de kraton, de ingang tot het eigentlijk paleis, en de plaats, waar de Vorst zijn bevelen aan de ambtenaren geeft of laat geven, en hun rapporten ontvangt of laat ontvangen.

(10) Waringin Binatoer worden twee Wringin boomen genoemd, die aan de zuidkant van de Noorder Aloenaloen vóór de Sitînggil staan.

(11) Martåloeloet is de naam van een kleine afdeeling pradjoerits van den Soesoehoenan, die belast is met de uitvoering van de doodvonnissen; zij. zijn slechts 15 in getal en behooren tot de regter vleugel (kaparaq tĕngĕn).

(12) Er bleven nog een paar jonge prinsen bij de Chinezen: de een was een zoon van Tepå Sånå, Mas Garĕndi geheeten, en dezelfde, die in de geschiedenis als Soenan Koening bekend is, nadat hij door de Chinezen tot Tegenkeizer was geproclameerd.

(13) Van deze kanonnen heb ik maar twee elders vermeld gevonden; Koemba aswani koemba of Aswani Koemba is de naam van een stuk, dat op de Aloen aloen staat bij de Waringin Binatoer (vgl. aant. 9). Ki Goentoer Gĕni komt in de overleveringen van de Javanen voor als afkomstig van de Hollanders, die daarvoor een schoone vrouw of prinses gekocht hebben. Vgl. Adji Såkå, p. 255, 7, en Bar. Sakènder pådå 637 .

(14) Sårå Gěni is de naam van een afdeeling Pradjoerits van den Vorst, 54 in getal, die mẹt geweren gewapend zijn, en voor hem uitgaan, als hij in het openbaar verschijnt

(15) De Kadipaten is het paleis van den Kroonprins (Pangeran Adipati Anom); thans ligt het te Soerakarta ten oosten van de kraton.

(16) Het woord, dat hier in het Javaansch wordt gebruikt, is de naam van het schutdak, dat bij de tijgergevechten in de kraton dient.

(17) Onder deze 450 man; zullen zeker ook de bedienden en koelis geteld zijn. De kleine minderheid werd door de soldaten gevormd, zooals ook blijkt uit het later genoemde getal van 117 geweren, die buitgemaakt waren.

Delft, Febr. 1863.

J. J. MEINSMA. 